\title{
The Next Wave
}

\author{
Susan R. Tortolero
}

Published online: 4 May 2013

(C) Springer Science+Business Media New York 2013

In 2009, when I became Editor-in-Chief of The Journal of Primary Prevention (JPP), the cover of the journal was redesigned to reflect the catalytic role of a drop of prevention in the pond of public health. To those of us in the field of prevention science, an old adage by Benjamin Franklin often comes to mind: "An ounce of prevention is worth a pound of cure." This unofficial motto of prevention researchers and practitioners codifies the ripple effect that investing in prevention can have on a population's health and wellbeing. Like such ripples, as the end of my tenure gives rise to the next wave of leadership, I am confident that $J P P$ will continue to expand its reach in the field of prevention science.

Being Editor-in-Chief of JPP has been an honor and a privilege, and I have been very grateful for the opportunity to guide the journal through several changes, both cosmetic and structural, during my tenure. In addition to receiving a new cover, the journal was expanded to accommodate more articles in each issue, with ample room to grow. The four article formats-original research, research methods and practice, brief reports, and literature reviewswere redefined and refined for greater clarity among authors and readers. I am proud to say that the journal received its first impact factor and that its stature has

S. R. Tortolero ( $\square)$

University of Texas School of Public Health, Houston, TX, USA

e-mail: Susan.Tortolero@uth.tmc.edu increased among prevention and public health journals: its impact factor increased from 1.090 to 1.542 . $J P P$ has also been successful at broadening its focus to include a wider range of public health topics while simultaneously maintaining a high threshold of scientific rigor for those studies accepted for publication.

These accomplishments are due to the hard work and dedication of many people to whom I must express my deep gratitude. First, I thank the members of the Editorial Board who stayed on when I came on board. Many of them have served as reviewers for and advisors to the journal for a very long time, and their continued support of JPP is much appreciated. Many thanks go to Ken McLeroy for continuing as an Associate Editor and providing valuable advice throughout my tenure. I also need to acknowledge newer additions to the Editorial Board, Elizabeth Baumler and Scott Carvajal, as well as Jeff Temple, Associate Editor, whose various expertise has helped - and will continue to help - the journal grow. In particular, I want to thank Melissa Peskin, Associate Editor, who worked alongside me to guide the journal's editorial direction. Her expertise and commitment have been invaluable to JPP.

On a day-to-day basis, Dennis Li, Editorial Assistant, and more recently Lionel Santibáñez, Copy Editor, were instrumental in every step of the peerreview and editorial process. Dennis is a doctoral candidate in Health Promotion and Behavioral Sciences at The University of Texas School of Public Health and will make an excellent research scientist. 
Lionel is a scientific editor with the Center for Health Promotion and Prevention Research and is a brilliant manuscript editor and talented writer. Both Dennis and Lionel were selflessly dedicated to the journal and brought skill, talent, and humor to this endeavor.

Lastly, I thank the staff and leadership at Springer but especially Khristine Queja, Editor for Public Health and JPP's Publishing Editor, who has supported me and the Associate Editors' efforts to make the journal such a strong publication and resource for prevention researchers and practitioners.

I leave this position knowing that JPP is in good shape and now in the capable hands of Dr. Christopher Ringwalt. Dr. Ringwalt, who has a 25-year history of studies related to public health, is based in Chapel Hill, NC, where he serves as a Senior Scientist at the Pacific
Institute for Research and Evaluation and as a Senior Evaluator at the Injury Prevention Research Center at The University of North Carolina. In discussions with my colleagues and me, Dr. Ringwalt has said he plans no substantive changes in the direction of JPP as a premier public health journal. Please join me in welcoming him to $J P P$.

I am happy to close out my tenure, coincidentally, with this special issue titled "Innovations in Primary Prevention." Original and groundbreaking research occurring throughout the nation are the catalysts that will help push public health and prevention science into a new era of addressing the world's wicked problems. I am confident that JPP will continue to publish innovative studies that will ripple outward and generate new waves of research in these fields. 